Supporting Information

of

\title{
Nanoparticle-Mediated Inhibition of Mitochondrial Glutaminolysis to Amplify Oxidative Stress for Combination Cancer Therapy
}

\author{
Lei Xu, ${ }^{a, b}$ Rui Xu, ${ }^{a, c}$ Phei Er Saw, ${ }^{a}$ Jun $W u,{ }^{c}$ Si-Xue Cheng, ${ }^{b}$ and Xiaoding $X u^{a *}$
}

[a] Guangdong Provincial Key Laboratory of Malignant Tumor Epigenetics and Gene

Regulation, Medical Research Center, Sun Yat-Sen Memorial Hospital, Sun Yat-Sen University, Guangzhou 510120, P. R. China

[b] Key Laboratory of Biomedical Polymers of Ministry of Education, Department of Chemistry, Wuhan University, Wuhan 430072, P. R. China

[c] School of Biomedical Engineering, Sun Yat-Sen University, Guangzhou 510120, P. R. China

* Corresponding authors: xuxiaod5@mail.sysu.edu.cn 


\section{Materials}

Bovine serum albumin (BSA) was purchased from Bovogen and used as received. Ferrocene and purpurin were provided by TCI and used directly. $N$-Hydroxysuccinimide (NHS), 1-(3-dimethylaminopropyl)-3-ethylcarbodiimide hydrochloride (EDC.HCl), and dimethyl sulfoxide (DMSO) were obtained from Sigma-Aldrich and used without further purification. Aptamer AS1411 (5'-COOH-( $\left.\mathrm{CH}_{2}\right)_{6}$-GGTGGTGGTGGTTGTGGTGGTGGTGG-3') with a terminal carboxyl acid group was provided by Sangon Biotech (Shanghai) Co. Ltd. GSH/GSSG ratio detection assay kit (ab138881), alpha-ketoglutarate ( $\alpha-K G)$ assay kit (ab83431), fumarate assay kit (ab102516), glutathione peroxidase 1 (GPx1) rabbit antibody (ab22604), glutamate dehydrogenase 1 (GDH1) rabbit antibody (ab153973), and Alexa Fluor 488 conjugated-nucleolin antibody (ab154028) were obtained from Abcam. 2',7'-Dichlorodihydrofluorescein diacetate (DFCH-DA) and Quant-iT ${ }^{\mathrm{TM}}$ OliGreen ${ }^{\circledR}$ ssDNA assay kit were provided by Thermo Fisher Scientific. BES- $\mathrm{H}_{2} \mathrm{O}_{2}$-Ac probe was purchased from Wako (Japan). $\beta$-Actin rabbit antibody (\#8457) and anti-rabbit IgG horseradish peroxidase (HRP)-linked secondary antibody (\#7074) were purchased from Cell Signaling Technology (CST). The $\bullet \mathrm{OH}$-specific probe was kindly provided by Dr. Hongyu Li from Chinese Academy of Sciences. Roswell Park Memorial Institute (RPMI) 1640 medium, penicillin, streptomycin, trypsin, and fetal bovine serum (FBS) were purchased from Invitrogen Corp. and used received. All other reagents and solvents are of analytical grade and used without further purification.

\section{Preparation and characterizations of BSA-based nanoparticles (NPs)}

The BSA-based NPs loading ferrocene and purpurin (denoted BFP NPs) were prepared according to our previous study based on the co-assembly of BSA, ferrocene, and purpurin [1]. In brief, $5 \mathrm{mg}$ of ferrocene and $5 \mathrm{mg}$ of purpurin were dissolved into $4 \mathrm{~mL}$ of DMSO to form homogeneous solution. Under vigorous stirring, $20 \mathrm{~mL}$ of BSA aqueous solution $(3.35 \mathrm{mg} / \mathrm{mL})$ 
was added dropwise. After stirring at $4{ }^{\circ} \mathrm{C}$ overnight, the NP suspension was transferred to an ultrafiltration device (EMD Millipore, MWCO $100 \mathrm{kDa}$ ) and centrifuged to remove the organic solvent and free compounds. After washing with deionized (DI) water $(3 \times 10 \mathrm{~mL})$, the obtained NPs were collected and freeze-dried for the following experiments. To prepare the aptamer-decorated BFP NPs (denoted ABFP NPs), $20 \mu \mathrm{L}$ of EDC aqueous solution $(0.1 \mathrm{mg} / \mathrm{mL})$ and $10 \mu \mathrm{L}$ of NHS aqueous solution $(0.1 \mathrm{mg} / \mathrm{mL})$ were mixed with $1 \mathrm{~mL}$ of aptamer AS1411 aqueous solution $(9.4 \mathrm{mmol} / \mathrm{L})$. After stirring at room temperature for $2 \mathrm{~h}$, the mixture was added to the suspension of the BFP NPs prepared according to the method described above. After gently stirring at $4{ }^{\circ} \mathrm{C}$ for $4 \mathrm{~h}$, the obtained ABFP NPs were purified using an ultrafiltration device (EMD Millipore, MWCO $100 \mathrm{kDa}$ ) and finally collected for freeze-drying. For the aptamer-decorated BSA-based NPs loading ferrocene (denoted ABF NPs) or purpurin (denoted ABP NPs), they were prepared according to the method aforementioned.

For the preparation of the fluorescence dye Cy5.5-labeled NPs (denoted Cy5.5-BFP NPs and Cy5.5-ABFP NPs), $10 \mathrm{mg}$ of the freeze-dried BFP or ABFP NPs were suspended in $5 \mathrm{~mL}$ of PBS solution ( $\mathrm{pH} 7.4$ ) and then Cy5.5 NHS ester (1 mg, $1.5 \mu \mathrm{mol}$, 10-fold molar excess compared to the amount of BSA in the NPs) dissolved in $0.5 \mathrm{~mL}$ of DMSO was added. After gently stirring at $4{ }^{\circ} \mathrm{C}$ overnight, the mixture was transferred to an ultrafiltration device (EMD Millipore, MWCO $100 \mathrm{kDa}$ ) and centrifuged to remove the organic solvent and free compounds. After washing with PBS solution $(\mathrm{pH} 7.4,3 \times 5 \mathrm{~mL})$, the obtained Cy5.5-labeled NPs were collected and freeze-dried under vacuum for the following experiments. Through examining the fluorescence intensity of Cy5.5 conjugated onto the NPs and comparing to the standard curve of Cy5.5, the number of Cy5.5 conjugated into the BFP and ABFP NPs was calculated as around $1.96 \times 10^{-4}$ and $1.27 \times 10^{-4}$ mol per gram NPs, respectively.

\section{Characterizations of the NPs}


The freeze-dried NPs $(1.5 \mathrm{mg})$ were suspended in $5 \mathrm{~mL}$ of DI water, and their size distribution and zeta potential were measured using a Nano-ZS ZEN3600 instrument (Malvern). The morphology of the NPs was visualized on a JEM-2100HR transmission electron microscope (TEM) and JEM-2010 scanning transmission electron microscope (SEM). Before the observation, $5 \mu \mathrm{L}$ of the NP suspension was applied to a copper grid and dried under air. Fourier transform infrared spectroscopy (FT-IR) spectra were recorded on a Perkin-Elmer FT-IR spectrophotometer. Before the measurement, the freeze-dried NPs were pressed into potassium bromide $(\mathrm{KBr})$ pellet. The elements in the freeze-dried NPs were analyzed by X-ray photoelectron spectroscopy (XPS) using an ESCALAB 250 X-ray photoelectron spectrometer. Ultraviolet-Visible (UV-Vis) absorbance spectra were examined using a Perkin-Elmer UV-Vis spectrophotometer (Lambda Bio40). To examine the encapsulation efficiency (EE\%) and loading level (LL\%) of ferrocene and purpurin, $2 \mathrm{mg}$ of the freeze-dried NPs were suspended in the mixture of DI water and DMSO (v/v, 1/9). After sonication in an ultrasonic bath sonicator for 10 min, the NP suspension was centrifuged and the amount of ferrocene and purpurin in the DMSO solution was determined through examining their UV absorption (325 nm for ferrocene and 486 $\mathrm{nm}$ for purpurin) and then calculating according to the standard curve. The EE\% and LL\% were calculated as: $\mathrm{EE} \%=($ amount of loaded cargo/amount of fed cargo $) \times 100 \%, \mathrm{LL} \%=($ amount of loaded cargo/amount of the cargo-loaded NPs) $\times 100 \%$. Herein, the encapsulation efficiency and loading level of purpurin or ferrocene in both BFP and ABFP NPs were determined as around $61.6 \%$ and $6.5 \%$ or $82.1 \%$ and $8.69 \%$. According to this loading level, the number of ferrocene and purpurin in the ABFP NPs could be calculated as around $4.78 \times 10^{-4}$ and $2.54 \times 10^{-4}$ mol per gram NPs, respectively. To examine the amount of aptamer AS1411 on the ABFP NPs, $1.5 \mathrm{mg}$ of the NPs were suspended in $5 \mathrm{~mL}$ of DI water and the commercial available Quant-iT ${ }^{\mathrm{TM}}$ OliGreen ${ }^{\circledR}$ ssDNA assay kit was used to examine the aptamer concentration according to the manufacturer's instructions. The final molar ratio between the aptamer and BSA 
is determined as around 1:66. According to the loading level of the ABFP NPs, the number of aptamer conjugated into the ABFP NPs could be calculated as $1.93 \times 10^{-7}$ mol per gram NPs.

\section{In vitro cargo release}

The freeze-dried NPs $(1.5 \mathrm{mg})$ were suspended in $5 \mathrm{~mL}$ of PBS solution and then transferred to a dialysis tube (MWCO $14 \mathrm{kDa}$ ) that immersed in $50 \mathrm{~mL}$ of PBS solution (pH 7.4 or 6.0 ) at $37^{\circ} \mathrm{C}$. At a predetermined time interval, $5 \mathrm{~mL}$ of PBS solution was withdrawn and $5 \mathrm{~mL}$ of fresh PBS solution was added after each sampling. The amount of ferrocene and purpurin released from the NPs was measured using a Perkin-Elmer UV-Vis spectrophotometer (Lambda Bio 40). The cumulative cargo release was calculated as follows:

$$
\text { Cumulative release }(\%)=\left(M_{t} / M_{\infty}\right) \times 100
$$

where $M_{t}$ is the amount of ferrocene or purpurin released from the NPs at time $t$ and $M_{\infty}$ is the amount of ferrocene or purpurin encapsulated into the NPs.

\section{Detection of hydroxyl radical $(\bullet \mathrm{OH})$ generation}

The freeze-dried BFP or ABFP NPs were suspended in $\mathrm{H}_{2} \mathrm{O}_{2}$-containing PBS solution ( $\mathrm{pH} 7.4$ or 6.0) at a purpurin and ferrocene concentration of 30 and $54 \mu \mathrm{M}$. Subsequently, the $\bullet \mathrm{OH}$-specific probe was added $(20 \mu \mathrm{M})$ and the mixture was allowed to incubate in dark at room temperature for $2 \mathrm{~h}$. Thereafter, the fluorescence emission spectra of the oxidized $\bullet \mathrm{OH}$-specific probe were examined $\left(E_{x}=570 \mathrm{~nm}, E_{m}=653 \mathrm{~nm}\right)$ to evaluate the ability of the NPs to catalyze $\mathrm{H}_{2} \mathrm{O}_{2}$ into $\bullet \mathrm{OH}[2]$

\section{Cell culture}

Human breast cancer cells (MCF-7) and human breast epithelial cells (MCF-10A) were incubated in RPMI 1640 medium with 10\% FBS and 1\% antibiotics (penicillin-streptomycin, 
$10,000 \mathrm{U} / \mathrm{mL}$ ) at $37{ }^{\circ} \mathrm{C}$ in a humidified atmosphere containing $5 \% \mathrm{CO}_{2}$.

\section{Detection of nucleolin expression}

MCF-7 and MCF-10A cells were seeded in 6 -well plate $\left(1 \times 10^{5}\right.$ cells/well $)$ respectively and incubated in $2 \mathrm{~mL}$ of RPMI 1640 medium containing 10\% FBS for $24 \mathrm{~h}$. Subsequently, the cells were digested by trypsin and collected through centrifugation $(250 \times \mathrm{g})$. After washing with PBS solution ( $\mathrm{pH} 7.4$ ), the cells were fixed with $4 \%$ paraformaldehyde for $15 \mathrm{~min}$. Thereafter, the cells were washed with PBS solution (pH 7.4) and then stained with Alexa Fluor 488-conjugated nucleolin antibody according to the manufacturer's instructions. After washing with PBS solution ( $\mathrm{pH}$ 7.4) thrice, the cells were collected for flow cytometry quantitative analysis (BD FACSAria $^{\mathrm{TM}}$ III Analyzer).

\section{Confocal laser scanning microscopy (CLSM)}

MCF-7 and MCF-10A cells $\left(1 \times 10^{5}\right.$ cells $)$ were seeded in a round dish respectively and incubated in $2 \mathrm{~mL}$ of RPMI 1640 medium containing 10\% FBS for $24 \mathrm{~h}$. After replacing the medium with $2 \mathrm{~mL}$ of fresh medium, the BFP or ABFP NPs suspended in PBS solution (pH 7.4) were added at a purpurin and ferrocene concentration of 30 and $54 \mu \mathrm{M}$. After $4 \mathrm{~h}$ incubation, the medium was removed and the cells were washed with PBS solution (pH 7.4) thrice. After staining the nuclei with Hoechst 33342, the cells were viewed under a Perkin-Elmer CLSM (UltraVIEW VoX).

\section{Flow cytometry}

MCF-7 and MCF-10A cells were seeded in 6-well plate $\left(1 \times 10^{5}\right.$ cells/well $)$ respectively and incubated in $2 \mathrm{~mL}$ of RPMI 1640 medium containing 10\% FBS for $24 \mathrm{~h}$. After replacing the medium with $2 \mathrm{~mL}$ of fresh medium, the BFP or ABFP NPs suspended in PBS solution ( $\mathrm{pH} 7.4)$ 
were added a purpurin and ferrocene concentration of 30 and $54 \mu \mathrm{M}$, and the cells were allowed to incubate for $4 \mathrm{~h}$. After removing the medium and subsequently washing with the PBS solution ( $\mathrm{pH}$ 7.4) thrice, the cells were digested by trypsin and collected for flow cytometry quantitative analysis (BD FACSAria ${ }^{\mathrm{TM}}$ III Analyzer).

\section{In vitro blockage of GDH1 activity}

MCF-7 cells were seeded in a 6-well plate $\left(1 \times 10^{5}\right.$ cells/well $)$ and incubated in $2 \mathrm{~mL}$ of RPMI 1640 medium containing 10\% FBS for $24 \mathrm{~h}$. After replacing the medium with $2 \mathrm{~mL}$ of fresh medium, the BFP or ABFP NPs suspended in PBS solution ( $\mathrm{pH} 7.4$ ) were added at a purpurin and ferrocene concentration of 30 and $54 \mu \mathrm{M}$, and the cells were allowed to incubate at $37^{\circ} \mathrm{C}$ for $12 \mathrm{~h}$. Subsequently, the cells were digested by trypsin and the proteins were extracted using modified radioimmunoprecipitation assay lysis buffer $(50 \mathrm{mM}$ Tris- $\mathrm{HCl} \mathrm{pH}$ 7.4, $150 \mathrm{mM} \mathrm{NaCl}$, $1 \%$ NP-40 substitute, $0.25 \%$ sodium deoxycholate, $1 \mathrm{mM}$ sodium fluoride, $1 \mathrm{mM} \mathrm{Na}_{3} \mathrm{VO}_{4}, 1 \mathrm{mM}$ EDTA), supplemented with protease inhibitor cocktail and $1 \mathrm{mM}$ phenylmethanesulfonyl fluoride (PMSF). The GDH1 expression was examined using the western blot analysis described below. The GDH1 expression in the cells treated with the ABP or ABF NPs at a purpurin or ferrocene concentration of 30 or $54 \mu \mathrm{M}$ were also examined by western blot. Before the analysis, the intracellular proteins were extracted according to the method described above.

\section{Western blot}

Equal amounts of protein, as determined with a bicinchoninic acid (BCA) protein assay kit (Thermo Scientific) according to the manufacturer's instructions, were added to SDS-PAGE gels and separated by gel electrophoresis. After transferring the proteins from gel to polyvinylidene difluoride membrane, the blots were blocked with 3\% BSA in TBST (50 mM Tris-HCl pH 7.4, $150 \mathrm{mM} \mathrm{NaCl}$, and $0.1 \%$ Tween 20 ) and then incubated with a mixture of GDH1 and $\beta$-actin 
rabbit antibody. The GDH1 expression was detected with horseradish peroxidase (HRP)-conjugated secondary antibody (anti-rabbit IgG HRP-linked antibody) and an enhanced chemiluminescence (ECL) detection system (Pierce).

\section{Detection of the metabolic intermediates of glutamine and intracellular GSG/GSSG} ratio

MCF-7 cells were seeded in 6-well plate $\left(1 \times 10^{5}\right.$ cells/well $)$ and incubated in $2 \mathrm{~mL}$ of RPMI 1640 medium containing 10\% FBS for $24 \mathrm{~h}$. After replacing the medium with $2 \mathrm{~mL}$ of fresh medium, the BFP or ABFP NPs suspended in the PBS solution were added a purpurin and ferrocene concentration of 30 and $54 \mu \mathrm{M}$, and the cells were allowed to incubate at $37^{\circ} \mathrm{C}$ for 12 h. Subsequently, the cells were digested by trypsin and $2 \times 10^{6}$ cells were homogenized in $50 \mu \mathrm{L}$ of PBS solution using the method of repeated freezing the liquid nitrogen and then thawing at room temperature. After centrifugation $(10000 \times \mathrm{g})$ at $4{ }^{\circ} \mathrm{C}$ for $10 \mathrm{~min}$, the supernatant was collected and the concentration of the metabolic intermediates of glutamine ( $\alpha-K G$ and fumarate) was examined using the $\alpha-\mathrm{KG}$ and fumarate assay kits according to the manufacturer's instructions. The intracellular GSH/GSSG ratio was also examined using the GSH/GSSG ratio detection assay kit according to the manufacturer's protocol. The concentration of $\alpha-K G$ and fumarate in the cells treated with the ABP or ABF NPs at a purpurin or ferrocene concentration of 30 or $54 \mu \mathrm{M}$ were also examined according to the method described above.

\section{Detection of intracellular level of $\mathrm{H}_{2} \mathrm{O}_{2}$ and $\bullet \mathrm{OH}$}

MCF-7 cells $\left(1 \times 10^{5}\right.$ cells $)$ were seeded in a round dish and incubated in $2 \mathrm{~mL}$ of RPMI 1640 medium containing 10\% FBS for $24 \mathrm{~h}$. After replacing the medium with $2 \mathrm{~mL}$ of fresh medium, the BFP or ABFP NPs suspended in PBS solution ( $\mathrm{pH}$ 7.4) were added a purpurin and ferrocene concentration of 30 and $54 \mu \mathrm{M}$, and the cells were allowed to incubate at $37{ }^{\circ} \mathrm{C}$ for $12 \mathrm{~h}$. 
Subsequently, the medium was replaced by fresh medium containing $\mathrm{H}_{2} \mathrm{O}_{2}$-specific fluorescent probe $\left(\mathrm{BES}-\mathrm{H}_{2} \mathrm{O}_{2}-\mathrm{Ac}, 30 \mu \mathrm{M}\right)$ or $\bullet \mathrm{OH}$-specific probe $(20 \mu \mathrm{M})$. After incubation for $30 \mathrm{~min}$, the cells were washed with the PBS solution $(\mathrm{pH}$ 7.4) thrice and then viewed under an inverted fluorescence microscope (Olympus IX80). The level of $\mathrm{H}_{2} \mathrm{O}_{2}$ and $\bullet \mathrm{OH}$ in the cells treated with the $\mathrm{ABP}$ or $\mathrm{ABF}$ NPs at a purpurin or ferrocene concentration of 30 or $54 \mu \mathrm{M}$ were also examined according to the method described above.

\section{Apoptosis assay}

MCF-7 cells $\left(1 \times 10^{5}\right.$ cells $)$ were seeded in a round dish and in incubated in $2 \mathrm{~mL}$ of RPMI 1640 medium containing 10\% FBS for $24 \mathrm{~h}$. After replacing the medium with $2 \mathrm{~mL}$ of fresh medium, the BFP or ABFP NPs suspended in PBS solution ( $\mathrm{pH} 7.4)$ were added a purpurin and ferrocene concentration of 30 and $54 \mu \mathrm{M}$, and the cells were allowed to incubate at $37{ }^{\circ} \mathrm{C}$ for $12 \mathrm{~h}$. Subsequently, the cells were digested by trypsin and the cells were collected for APC-A750A and FITC Annexin V staining using the commercial available apoptosis detection kit. The apoptosis analysis was performed using a BD FACSAria ${ }^{\mathrm{TM}}$ III Analyzer. The apoptosis of the cells treated with the ABP or ABF NPs at a purpurin or ferrocene concentration of 30 or $54 \mu \mathrm{M}$ were also analyzed by flow cytometry according to the method described above.

\section{Cytotoxicity}

MCF-7 and MCF-10A cells were seeded in 96-well plate (5000 cells/well) respectively and incubated in $100 \mu \mathrm{L}$ of RPMI 1640 medium containing 10\% FBS for $24 \mathrm{~h}$. After replacing the medium with $100 \mu \mathrm{L}$ of fresh medium, the NPs suspended in PBS solution (pH 7.4) were added and the cells were allowed to incubate at $37{ }^{\circ} \mathrm{C}$ for $24 \mathrm{~h}$. Thereafter, the medium was removed and the mixture of fresh medium without FBS $(90 \mu \mathrm{L})$ and AlamarBlue solution $(10 \mu \mathrm{L})$ was added to each well. After incubation at $37{ }^{\circ} \mathrm{C}$ for $1 \mathrm{~h}$, the fluorescence intensity $\left(E_{x}=530 \mathrm{~nm}, E_{m}\right.$ 
$=590 \mathrm{~nm}$ ) was measured by Synergy HT multi-mode microplate reader. The average value of three independent experiments was collected and the cell viability was calculated as follows:

$$
\text { Cell viability }(\%)=\left(\mathrm{FI}_{\text {treated }} / \mathrm{FI}_{\text {control }}\right) \times 100
$$

where $\mathrm{FI}_{\text {control }}$ is the fluorescence intensity obtained in the absence of the NPs and $\mathrm{FI}_{\text {treated }}$ is fluorescence intensity obtained in the presence of the NPs.

\section{Animals}

Female BALB/c normal mice and nude mice (5-6 weeks old) were purchased from Biosafety Level 3 Animal Laboratory at Wuhan University. All in vivo studies were performed in accordance with a protocol approved by the Institutional Animal Care and Use Committee at Wuhan University.

\section{Pharmacokinetics study}

Healthy female BALB/c normal mice were randomly divided into two groups $(n=3)$ and given an intravenous injection of either (i) Cy5.5-BFP NPs, or (ii) Cy5.5-ABFP NPs at a dose of 175 $\mathrm{mg} / \mathrm{kg} \quad(1.5 \mathrm{mg} / \mathrm{kg}$ ferrocene-equivalent and $1.1 \mathrm{mg} / \mathrm{kg}$ purpurin-equivalent dose). At predetermined time intervals, $20 \mu \mathrm{L}$ of orbital vein blood was withdrawn using a tube containing heparin, and the wound was pressed for several seconds to stop the bleeding. The fluorescence intensity of Cy5.5-labeled NPs in the blood was determined by a microplate reader. The half-life $\left(t_{1 / 2}\right)$ was calculated according to the blood circulation profile of the NPs.

\section{MCF-7 xenograft tumor model}

MCF-7 xenograft tumor model was constructed by subcutaneous injection with $200 \mu \mathrm{L}$ of MCF-7 cell suspension (a mixture of RPMI 1640 medium and Matrigel in 1:1 volume ratio) with a density $1 \times 10^{7}$ cells $/ \mathrm{mL}$ into the back region of healthy female nude mice. When the tumor 
volume reached $\sim 100 \mathrm{~mm}^{3}$, the mice were used for the following in vivo experiments.

\section{Biodistribution}

MCF-7 xenograft tumor-bearing mice were randomly divided into two groups $(n=3)$ and given an intravenous injection of either (i) Cy5.5-BFP NPs, or (ii) Cy5.5-ABFP NPs at a dose of 175 $\mathrm{mg} / \mathrm{kg}(1.5 \mathrm{mg} / \mathrm{kg}$ ferrocene-equivalent and $1.1 \mathrm{mg} / \mathrm{kg}$ purpurin-equivalent dose). Twenty-four hours after the injection, the mice were imaged using the SmartChemiTM 910plus Chemi System (SAGECREATION, China). Organs and tumors were then harvested and imaged. To quantify the NP accumulation in the tumors and organs, the fluorescence intensity of each tissue was quantified by Image-J.

\section{Magnetic resonance imaging (MRI)}

The freeze-dried ABFP NPs were suspended in $\mathrm{H}_{2} \mathrm{O}_{2}$-containing $(100 \mu \mathrm{M})$ PBS solution (pH 6.0) at different ferrocene concentrations. After incubation at room temperature for $2 \mathrm{~h}$, the $\mathrm{T}_{2}$-weighted MRI and the signal intensity were measured using a $4.7 \mathrm{~T}$ small animal MRI instrument (Bruker BioSpin). The parameters were set as: scan: 5, slice: 3/4, echo: 1/1, Tr: $2000.0 \mathrm{~ms}$, Te: $30.0 \mathrm{~ms}$, field of view: $2.5 \mathrm{~cm}$, number of excitations: 4 , lip angle: $90^{\circ}$.

The in vivo $\mathrm{T}_{1}$-weighted MRI was examined by intratumoral injection of the ABFP NPs into MCF-7 xenograft tumor-bearing mice at a dose of $175 \mathrm{mg} / \mathrm{kg}(1.5 \mathrm{mg} / \mathrm{kg}$ ferrocene-equivalent and $1.1 \mathrm{mg} / \mathrm{kg}$ purpurin-equivalent dose). $\mathrm{T}_{1}$-weighted MRI of the tumor tissues was observed at different time intervals using a $4.7 \mathrm{~T}$ small animal MRI instrument. The parameters were set as: scan: 3, slice: 11/16, echo: 1/1, Tr: $500.0 \mathrm{~ms}$, Te: $6.0 \mathrm{~ms}$, field of view: $3.5 \mathrm{~cm}$, number of excitations: 8 , flip angle: $90^{\circ}$. The in vivo $\mathrm{T}_{2}$-weighted MRI was examined by intravenous injection of the ABFP NPs into MCF-7 xenograft tumor-bearing mice at a dose of $175 \mathrm{mg} / \mathrm{kg}$ ( $1.5 \mathrm{mg} / \mathrm{kg}$ ferrocene-equivalent and $1.1 \mathrm{mg} / \mathrm{kg}$ purpurin-equivalent dose). $\mathrm{T}_{2}$-weighted MRI of 
the tumor tissues was observed at different time intervals using a $4.7 \mathrm{~T}$ small animal MRI instrument. The parameters were set as: scan: 3, slice: 10/16, echo: $1 / 1$, Tr: $2000.0 \mathrm{~ms}$, Te: 40.0 ms, field of view: $3.5 \mathrm{~cm}$, number of excitations: 4 , flip angle: $90^{\circ}$.

\section{In vivo blockage of GDH1 activity}

MCF-7 xenograft tumor-bearing mice were randomly divided into five groups $(n=3)$ and given an intravenous injection of either (i) $100 \mu \mathrm{L}$ of PBS solution (pH 7.4), (ii) ABF NPs (1.5 mg/kg ferrocene-equivalent dose), (iii) ABP NPs (1.1 mg/kg purpurin-equivalent dose), (vi) BFP NPs (1.5 mg/kg ferrocene-equivalent and $1.1 \mathrm{mg} / \mathrm{kg}$ purpurin-equivalent dose), or (v) ABFP NPs (1.5 $\mathrm{mg} / \mathrm{kg}$ ferrocene-equivalent and $1.1 \mathrm{mg} / \mathrm{kg}$ purpurin-equivalent dose). Twenty-four hours after the injection, the mice were sacrificed and tumors were harvested. The proteins in the tumor were extracted using modified radioimmunoprecipitation assay lysis buffer $(50 \mathrm{mM}$ Tris- $\mathrm{HCl} \mathrm{pH}$ 7.4, $150 \mathrm{mM} \mathrm{NaCl}, 1 \% \mathrm{NP}-40$ substitute, $0.25 \%$ sodium deoxycholate, $1 \mathrm{mM}$ sodium fluoride, 1 $\mathrm{mM} \mathrm{Na} \mathrm{VO}_{4}, 1 \mathrm{mM}$ EDTA), supplemented with protease inhibitor cocktail and $1 \mathrm{mM}$ PMSF. The GDH1 expression in the tumor tissues was examined using western blot.

\section{In vivo detection of the metabolic intermediates of glutamine and GSG/GSSG ratio}

After in vivo blockage of GDH1 activity, $50 \mathrm{mg}$ of the fresh tumor tissues was homogenized in $500 \mu \mathrm{L}$ of PBS solution ( $\mathrm{pH} 7.4)$ on ice using a homogenizer. After centrifugation $(10000 \times \mathrm{g})$ at $4{ }^{\circ} \mathrm{C}$ for $10 \mathrm{~min}$, the supernatant was collected and the concentration of the metabolic intermediates of glutamine ( $\alpha-\mathrm{KG}$ and fumarate) was examined using the $\alpha-\mathrm{KG}$ and fumarate assay kits according to the manufacturer's instructions. The GSH/GSSG ratio was also examined using the GSH/GSSG ratio detection assay kit according to the manufacturer's protocol.

\section{Inhibition of tumor growth}


MCF-7 xenograft tumor-bearing mice were randomly divided into five groups $(\mathrm{n}=5)$ and intravenously injected with (i) $100 \mu \mathrm{L}$ of PBS solution (pH 7.4), (ii) ABF NPs (1.5 mg/kg ferrocene-equivalent dose), (iii) ABP NPs (1.1 mg/kg purpurin-equivalent dose), (vi) BFP NPs (1.5 mg/kg ferrocene-equivalent and $1.1 \mathrm{mg} / \mathrm{kg}$ purpurin-equivalent dose), or (v) ABFP NPs (1.5 $\mathrm{mg} / \mathrm{kg}$ ferrocene-equivalent and $1.1 \mathrm{mg} / \mathrm{kg}$ purpurin-equivalent dose) every two days. All the mice were administrated by two consecutive injections and the tumor growth was monitored every two days by measuring perpendicular diameters using a caliper and tumor volume was calculated as follows: $\mathrm{V}=\mathrm{W}^{2} \times \mathrm{L} / 2$, where $\mathrm{W}$ and $\mathrm{L}$ are the shortest and longest diameters, respectively.

\section{Histology}

After the aforementioned treatment by (i) PBS, (ii) ABF NPs, (iii) ABP NPs, (vi) BFP NPs, or (v) ABFP NPs, the mice were sacrificed at end of the evaluation period, and the tumors and main organs were collected. After fixing with $4 \%$ paraformaldehyde and then embedding in paraffin, the tissue was sectioned and stained with hematoxylin-eosin $(\mathrm{H} \& \mathrm{E})$ and then viewed under an optical microscope. In addition, the tumor tissue section was stained by terminal deoxynucleotidyl transferase dUTP nick end labeling (TUNEL) according to the manufactory's protocol and viewed under a Perkin-Elmer CLSM.

\section{Immunofluorescence staining}

The slices containing tumor sections was heated at $60{ }^{\circ} \mathrm{C}$ for $1 \mathrm{~h}$ and washed with xylene, ethanol, and PBS thrice. After blocking with 10\% FBS for $1.5 \mathrm{~h}$, the slices were incubated with caspase- 3 or Ki67 antibody at $4{ }^{\circ} \mathrm{C}$ for $1 \mathrm{~h}$. After washing with PBS/0.2\% triton $\mathrm{X}-100$ thrice, Alexa Flour 488-conjugated secondary antibody (Goat anti-rat IgG) was added for $1 \mathrm{~h}$ to stain the slices. Thereafter, the slices were washed with PBS thrice and then stained with Hoechst 
33342. The expression of caspase-3 and Ki67 was viewed under a Perkin-Elmer CLSM.

\section{Immune response}

Healthy female BALB/c normal mice were randomly divided into five groups $(n=3)$ and given an intravenous injection of either (i) $100 \mu \mathrm{L}$ of PBS solution (pH 7.4), (ii) ABF NPs (1.5 mg/kg ferrocene-equivalent dose), (iii) ABP NPs (1.1 mg/kg purpurin-equivalent dose), (vi) BFP NPs (1.5 mg/kg ferrocene-equivalent and $1.1 \mathrm{mg} / \mathrm{kg}$ purpurin-equivalent dose), or (v) ABFP NPs (1.5 $\mathrm{mg} / \mathrm{kg}$ ferrocene-equivalent and $1.1 \mathrm{mg} / \mathrm{kg}$ purpurin-equivalent dose). Twenty-four hours after injection, blood was collected and serum was isolated for the detection of representative cytokines (TNF- $\alpha$, IL-6, IL-12, and IFN- $\gamma$ ) by enzyme-linked immunosorbent assay or ELISA (PBL Biomedical Laboratories and BD Biosciences) according to the manufacturer's instructions.

\section{Blood analysis}

Healthy female BALB/c mice were randomly divided into five groups $(n=3)$ and given an intravenous injection of either (i) $100 \mu \mathrm{L}$ of PBS solution (pH 7.4), (ii) ABF NPs $(1.5 \mathrm{mg} / \mathrm{kg}$ ferrocene-equivalent dose), (iii) ABP NPs (1.1 mg/kg purpurin-equivalent dose), (vi) BFP NPs (1.5 mg/kg ferrocene-equivalent and $1.1 \mathrm{mg} / \mathrm{kg}$ purpurin-equivalent dose), or (v) ABFP NPs (1.5 $\mathrm{mg} / \mathrm{kg}$ ferrocene-equivalent and $1.1 \mathrm{mg} / \mathrm{kg}$ purpurin-equivalent dose). After three consecutive injections, the blood was collected at $24 \mathrm{~h}$ post the final injection and serum was isolated for detection of representative blood parameters (AST, ALT, ALKP, creatinine, urea and total protein).

\section{Statistical Analysis}

Statistical significance was determined by a two-tailed Student's $t$ test assuming equal variance. 
A $p$ value $<0.05$ is considered statistically significant.

\section{References}

[1] Xu, L.; Wang, S.-B.; Xu, C.; Han, D.; Ren, X.-H.; Zhang, X.-Z.; Cheng, S.-X., Multifunctional Albumin-Based Delivery System Generated by Programmed Assembly for Tumor-Targeted Multimodal Therapy and Imaging. ACS Appl. Mater. Interfaces 2019, 11, $38385-38394$

[2] Li, H.; Li, X.; Shi, W.; Xu, Y.; Ma, H., Rationally Designed Fluorescence •OH Probe with High Sensitivity and Selectivity for Monitoring the Generation of $\bullet \mathrm{OH}$ in Iron Autoxidation without Addition of $\mathrm{H}_{2} \mathrm{O}_{2}$. Angew. Chem. Int. Ed. 2018, 57, 12830-12834. 


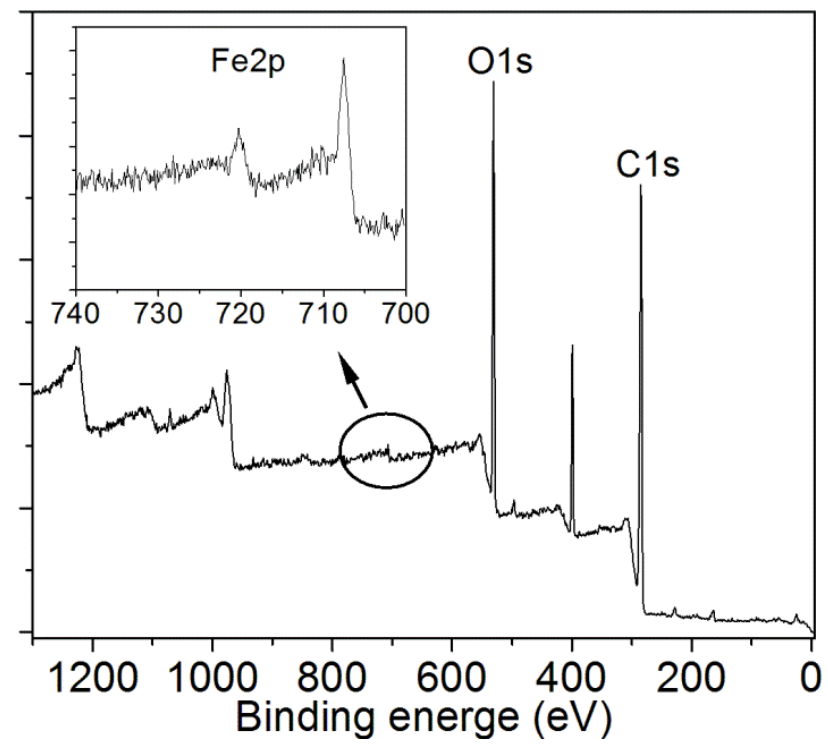

Figure S1. XPS spectrum of the BFP NPs.
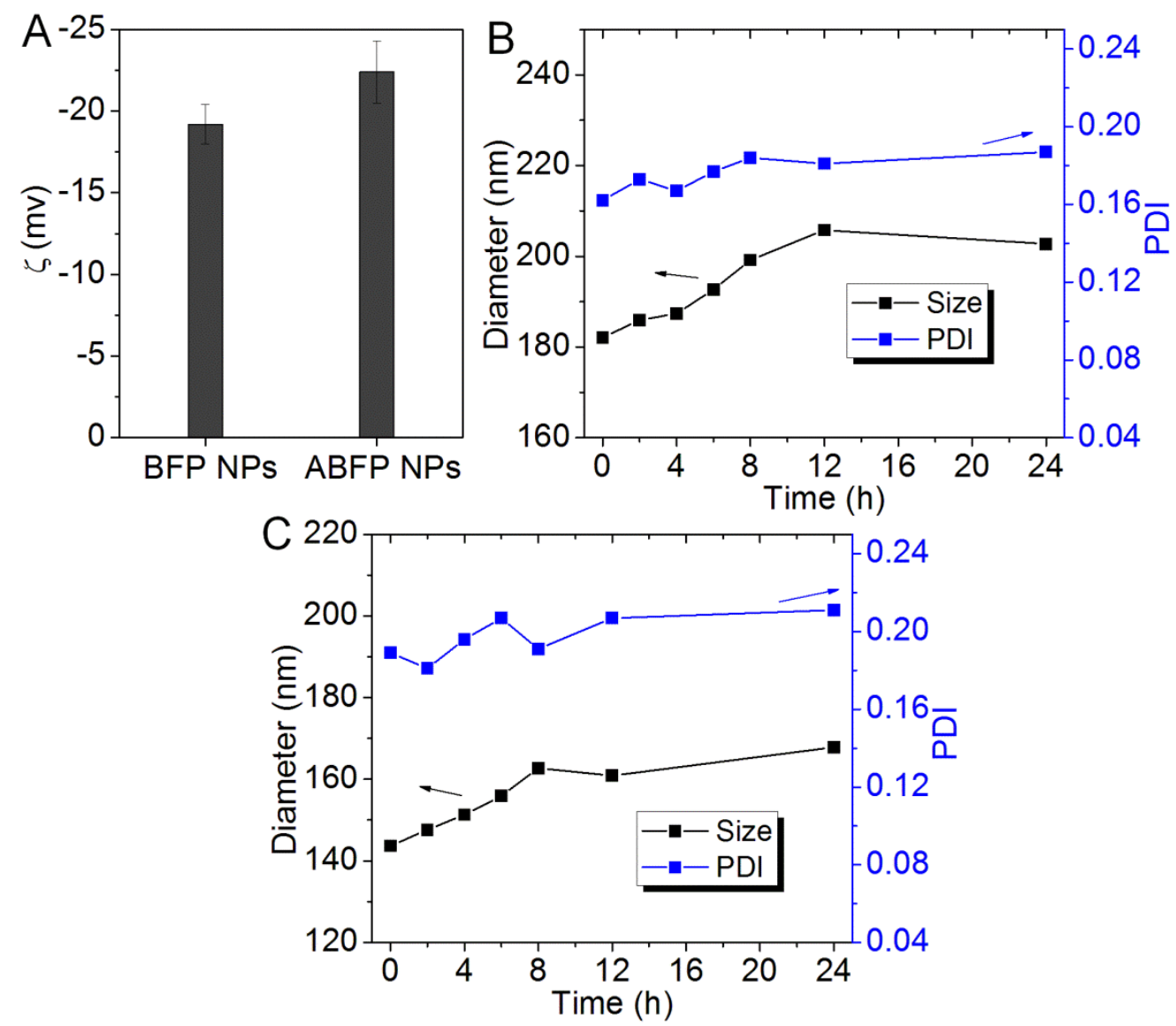

Figure S2. (A) Zeta potential of the BFP and ABFP NPs. (B, C) Size change of the BFP (B) and ABFP NPs $(\mathrm{C})$ incubated in PBS solution ( $\mathrm{pH} 7.4)$ containing $10 \%$ FBS for different times. 




Figure S3. Cumulative release of ferrocene and purpurin from the ABFP NPs incubated in PBS solution ( $\mathrm{pH}$ 7.4) containing $100 \mu \mathrm{M}$ of $\mathrm{H}_{2} \mathrm{O}_{2}$.
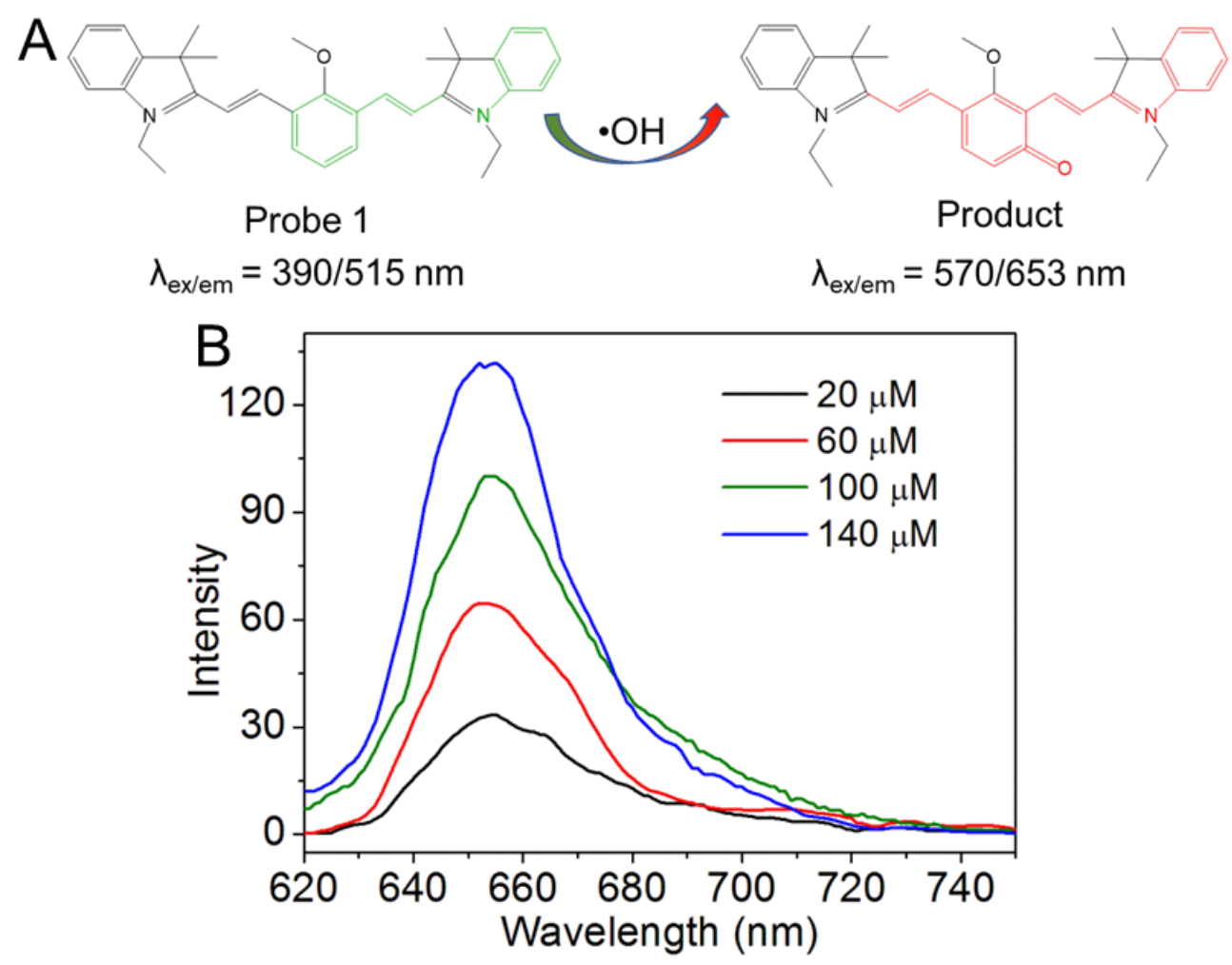

Figure S4. (A) Fluorescent off-on mechanism of the $\bullet \mathrm{OH}$-specific probe. (B) Fluorescence emission spectra of the $\cdot \mathrm{OH}$-specific probe incubated with the mixture of ABFP NPs and $\mathrm{H}_{2} \mathrm{O}_{2}$ $(20,60,100$, and $140 \mu \mathrm{M})$ at $\mathrm{pH} 6.0$ for $2 \mathrm{~h}$. 

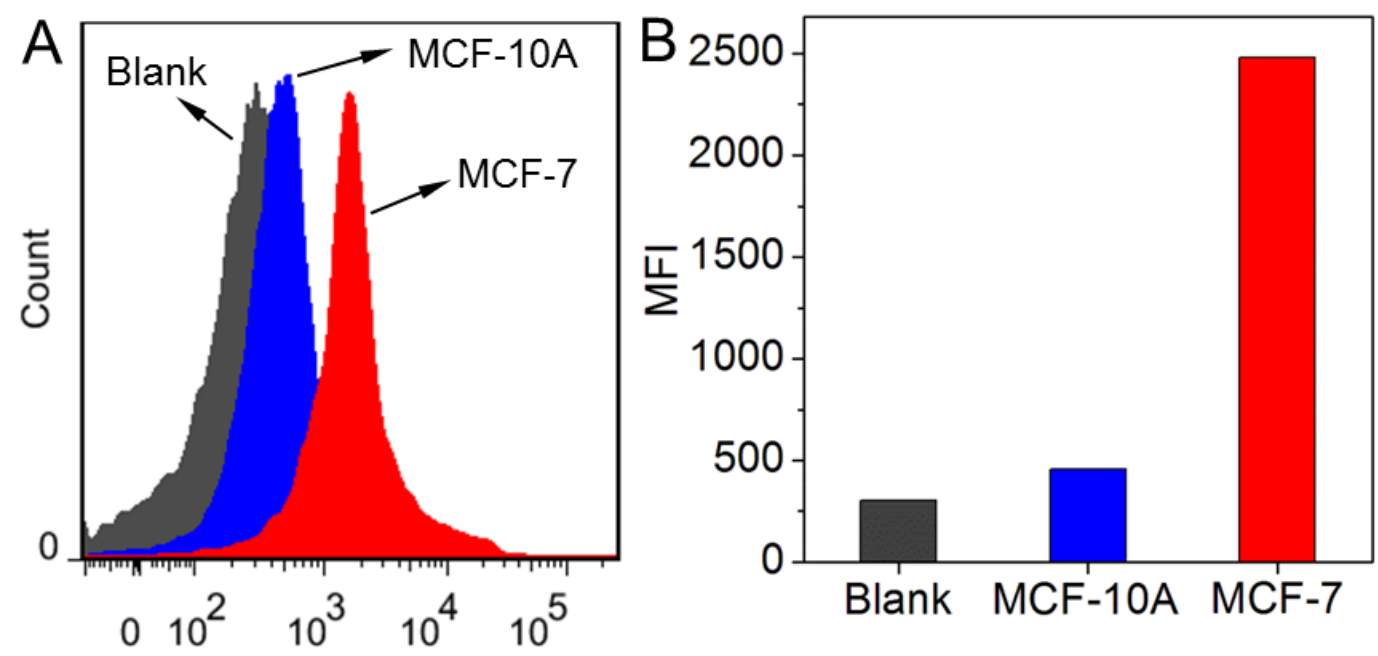

Figure S5. Flow cytometry profile (A) and mean fluorescence intensity (MFI, B) of MCF-10A and MCF-7 cells incubated with Alexa Fluor 488-conjugated nucleolin antibody.
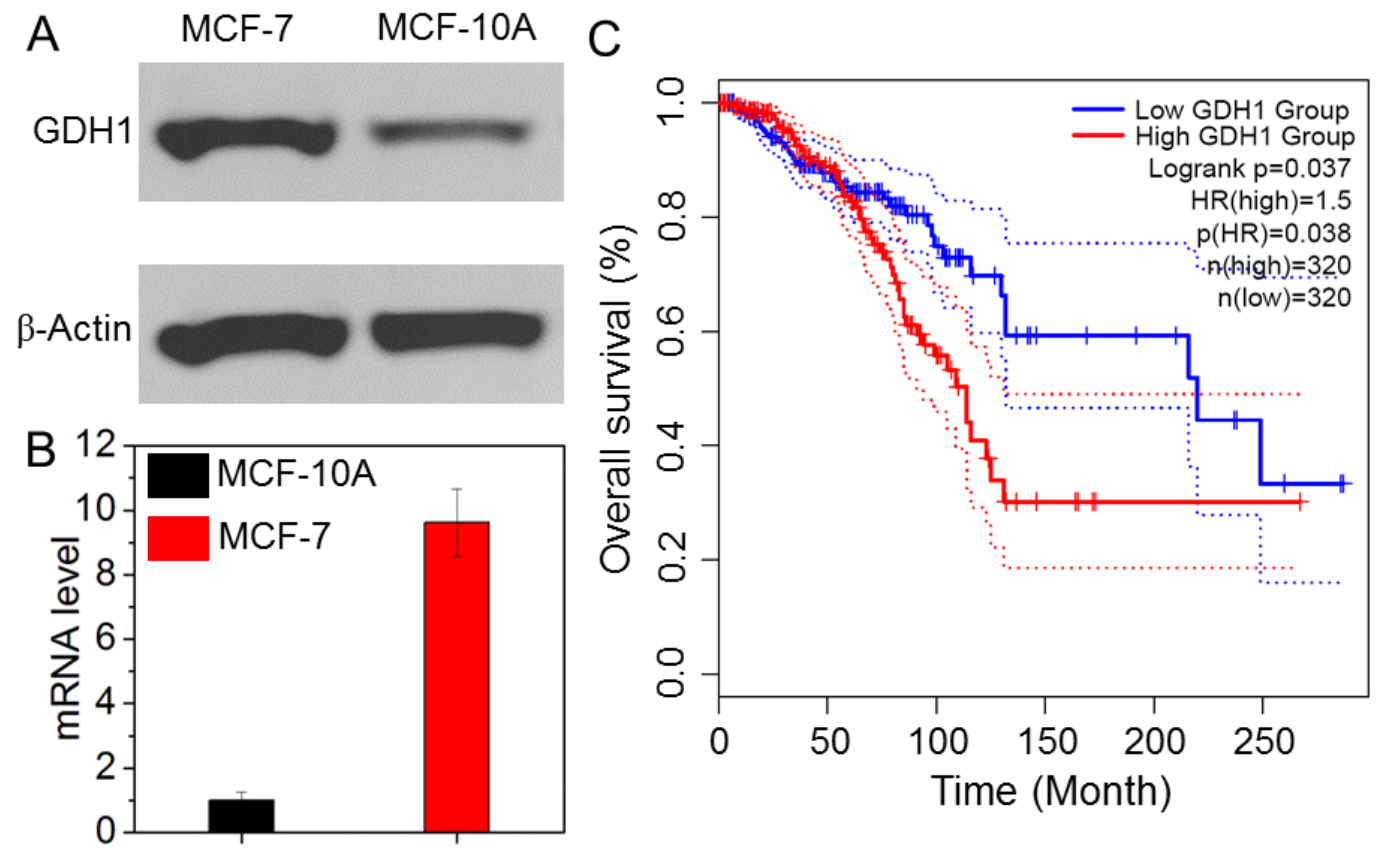

Figure S6. (A, B)The expression of GDH1 protein determined by western blot (A) and GDH1 mRNA determined by qRT-PCR (B) in MCF-7 and MCF-10A cells. (C) The Cancer Genome Atlas (TCGA) database showing the overall survival of breast cancer patients $(n=640)$ with different levels of GDH1 expression. 


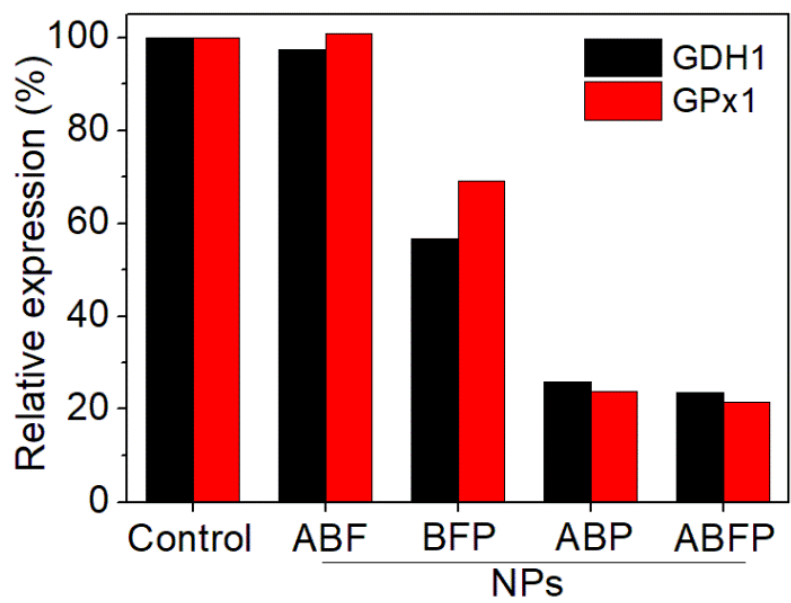

Figure S7. Relative expression of GDH1 and GPx1 determined by western blot analysis of

MCF-7 cells treated with the ABP, ABF, BFP, and ABFP NPs at a purpurin and ferrocene concentration of 30 and $54 \mu \mathrm{M}$, respectively. The cells incubated with free medium were used as a control.



Figure S8. CLSM images of MCF-7 cells treated with the ABP, ABF, BFP, and ABFP NPs at a purpurin and ferrocene concentration of 30 and $54 \mu \mathrm{M}$, respectively. The cells incubated with free medium were used as a control. 


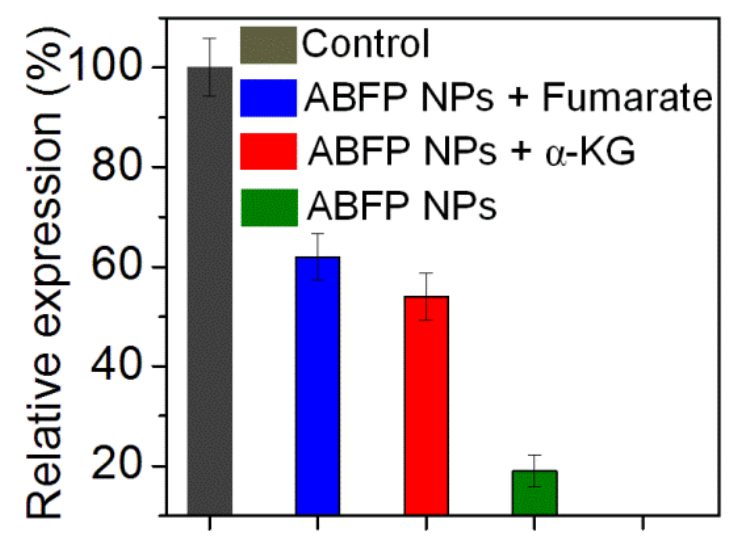

Figure S9. Relative GPx1 mRNA level determined by reverse transcription quantitative polymerase chain reaction (qRT-PCR) analysis of MCF-7 cells treated with the mixture of ABFP NPs and $\alpha-K G(60 \mu \mathrm{M})$ or fumarate $(60 \mu \mathrm{M})$ for $4 \mathrm{~h}$. The cells incubated with free medium were used as a control.

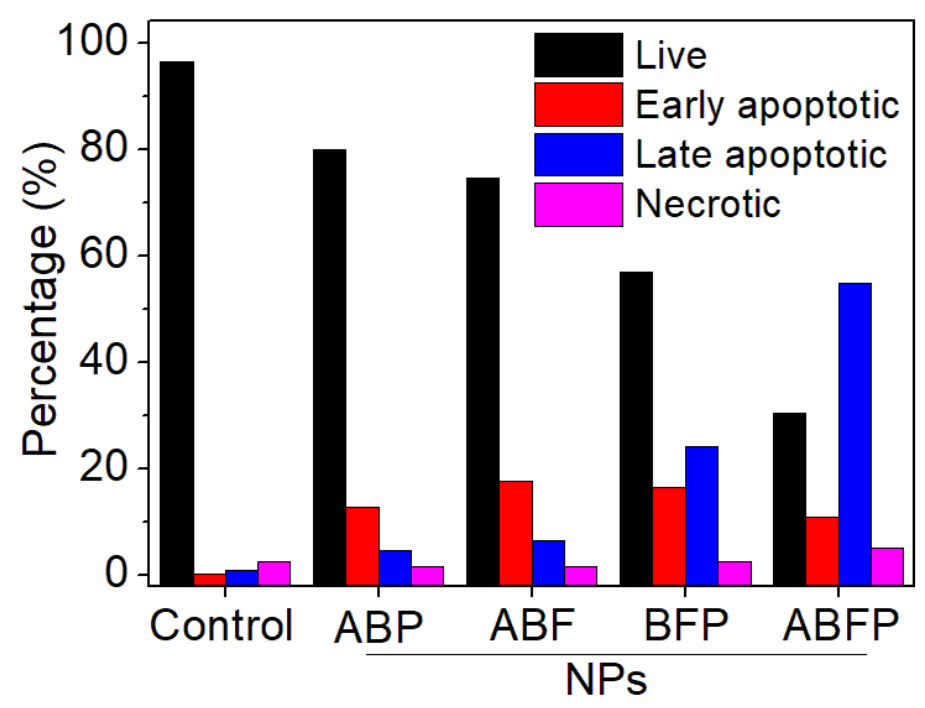

Figure S10. Quantification of apoptosis determined by flow cytometry analysis of MCF-7 cells treated with the $\mathrm{ABP}, \mathrm{ABF}, \mathrm{BFP}$, and $\mathrm{ABFP}$ NPs at a purpurin and ferrocene concentration of 30 and $54 \mu \mathrm{M}$, respectively. The cells incubated with free medium were used as a control. 


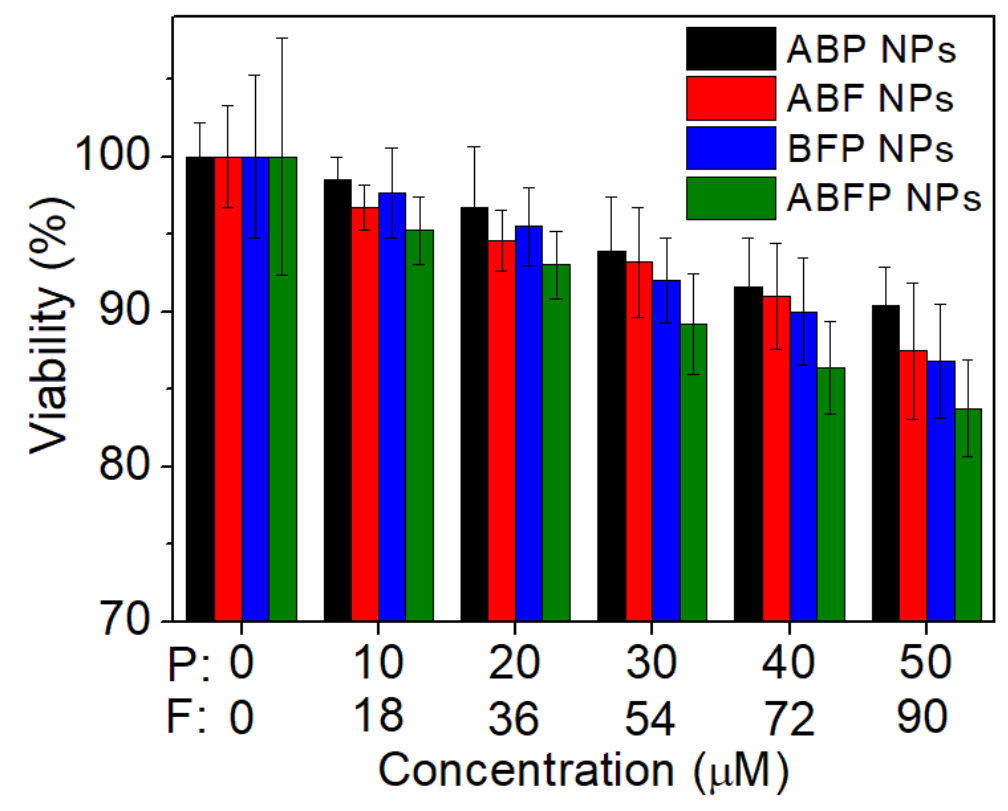

Figure S11. Viability of MCF-10A cells treated with the ABP, ABF, BFP, and ABFP NPs at different concentrations of purpurin $(\mathrm{P})$ and ferrocene $(\mathrm{F})$, respectively.

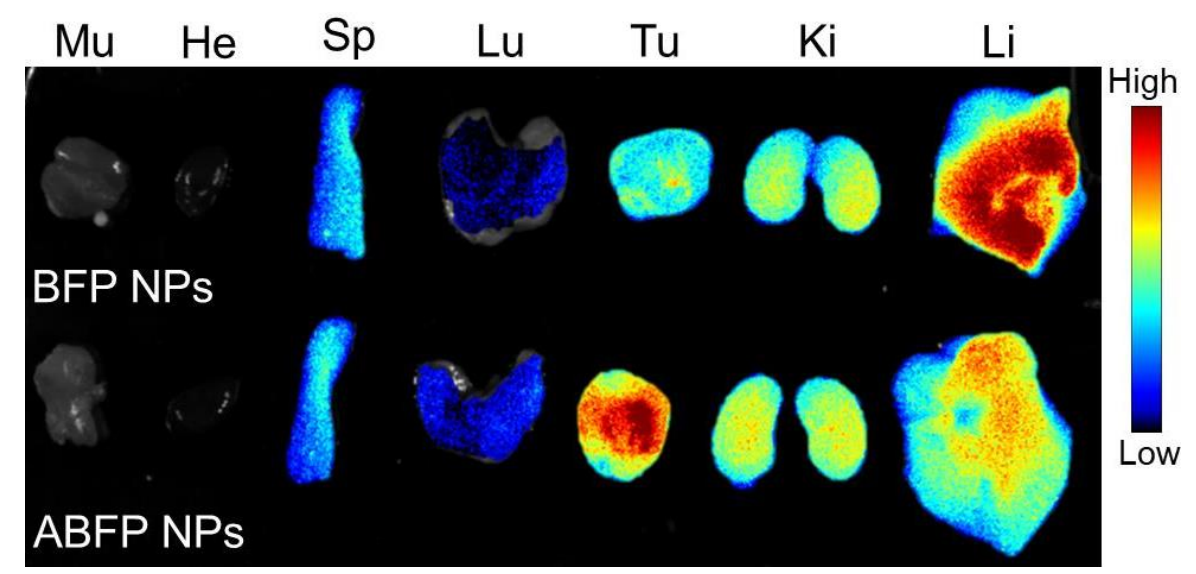

Figure S12. Overlaid fluorescence image of the tumors and main organs of MCF-7 xenograft tumor-bearing mice at $24 \mathrm{~h}$ post injection of the BFP and ABFP NPs. Mu, $\mathrm{He}, \mathrm{Sp}, \mathrm{Lu}, \mathrm{Tu}, \mathrm{Ki}$, and Li represent the muscle, heart, spleen, lung, tumor, kidney, and liver, respectively. 


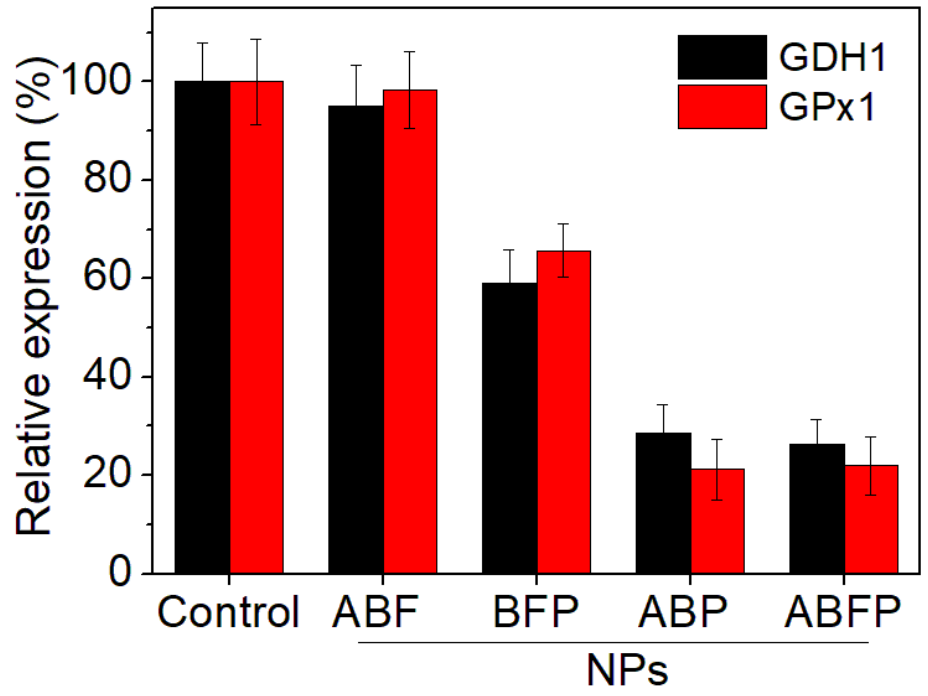

Figure S13. Relative expression of GDH1 and GPx 1 determined by western blot analysis of the tumor tissues of MCF-7 xenograft tumor-bearing mice treated with PBS, and the ABP, ABF, BFP, and ABFP NPs.

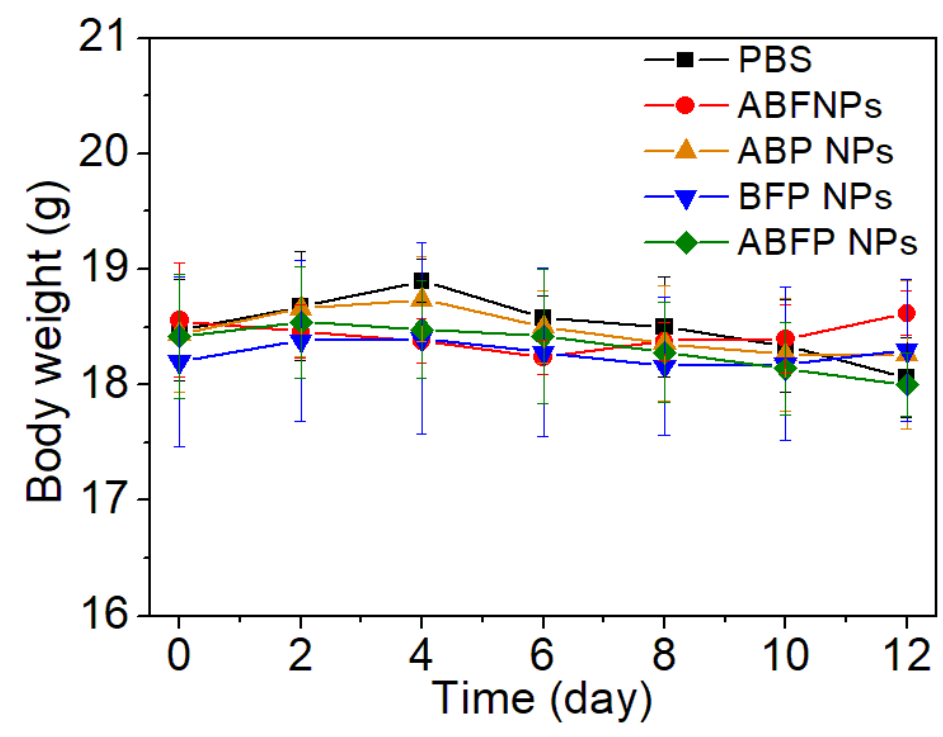

Figure S14. Body weight of MCF-7 xenograft tumor-bearing mice treated with PBS, and the $\mathrm{ABF}, \mathrm{ABP}, \mathrm{BFP}$, and ABFP NPs. 


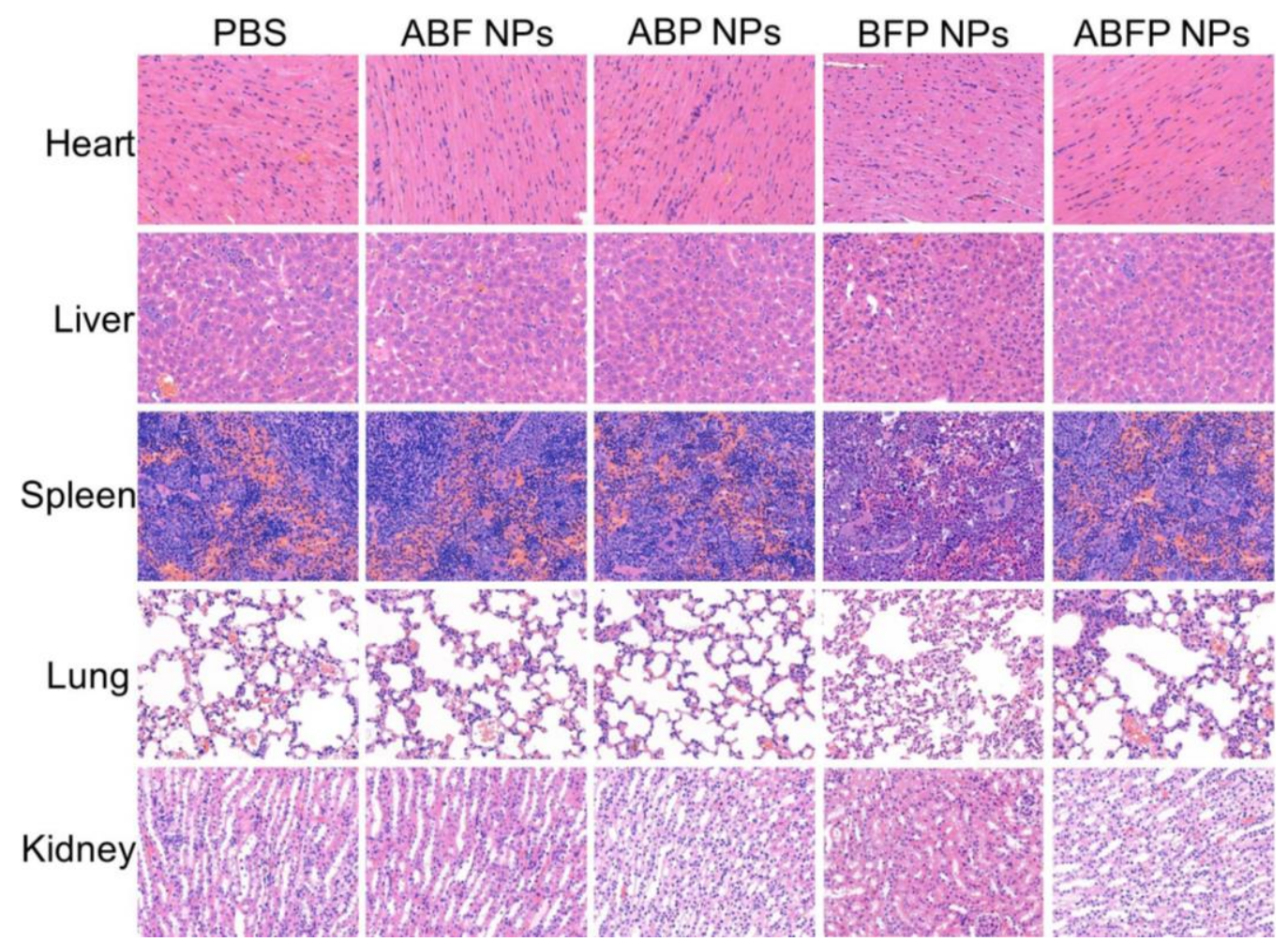

Figure S15. Histological section of the major organs of MCF-7 xenograft tumor-bearing mice treated with PBS, and the ABF, ABP, BFP, and ABFP NPs. magnification $100 \times$
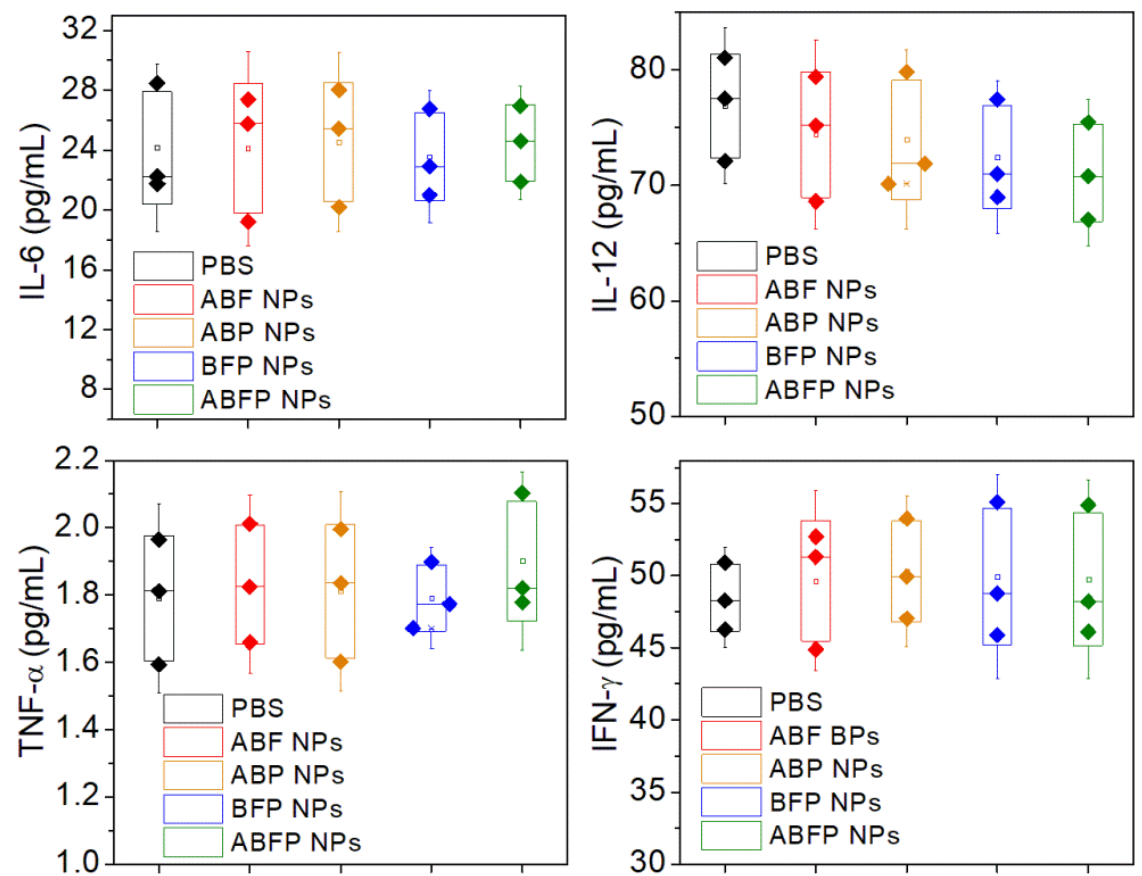

Figure S16. Serum levels of IL-6, IL-12, TNF- $\alpha$, and IFN- $\gamma$ at 24 h post injection of PBS, and the ABF, ABP, BFP, and ABFP NPs. 

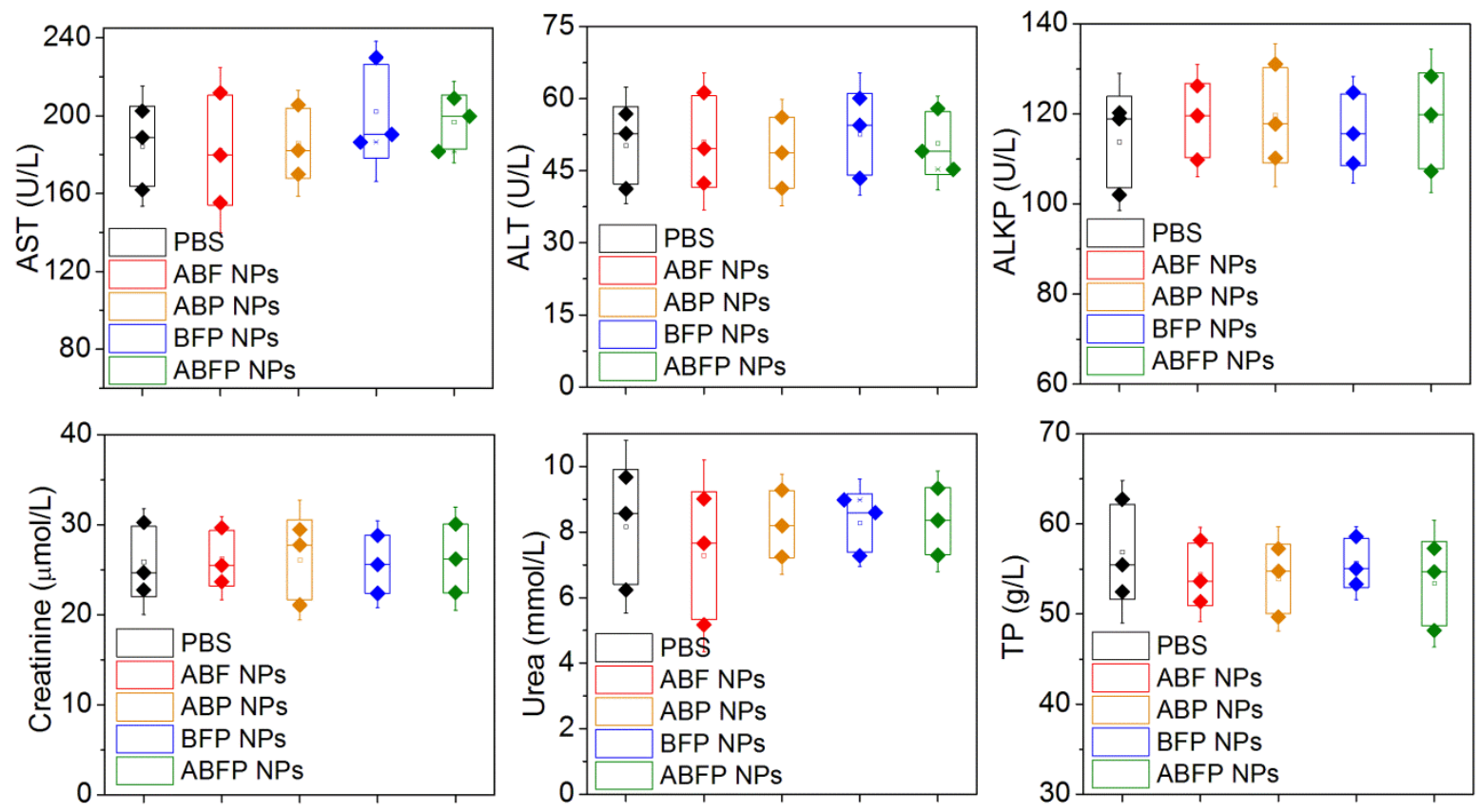

Figure S17. Serum levels of aspartate aminotransferase (AST), alanine aminotransferase (ALT), albumin, alkaline phosphatase (ALKP), creatinine, urea, and total protein (TP) after three consecutive injections of PBS, and the ABF, ABP, BFP, and ABFP NPs. 